\title{
Intracellular ATP Increases Capsaicin-Activated Channel Activity by Interacting with Nucleotide-Binding Domains
}

\author{
Jiyeon Kwak, ${ }^{1}$ Myeong Hyeon Wang, ${ }^{1}$ Sun Wook Hwang, ${ }^{1}$ Tae-Yoon Kim, ${ }^{2}$ Soon-Youl Lee, ${ }^{1}$ and Uhtaek Oh 1 \\ ${ }^{1}$ Sensory Research Group, Creative Research Initiatives, Seoul National University, College of Pharmacy, Kwanak, Shinlim \\ San 56-1, Seoul 151-742, Korea, and 'Department of Immunology and Dermatology, College of Medicine, Catholic \\ University, Seoul 137-040, Korea
}

Capsaicin (CAP)-activated ion channel plays a key role in generating nociceptive neural signals in sensory neurons. Here we present evidence that intracellular ATP upregulates the activity of capsaicin receptor channel. In inside-out membrane patches isolated from sensory neurons, application of CAP activated a nonselective cation channel $\left(i_{\text {cap }}\right)$. Further addition of ATP to the bath caused a significant increase in $i_{\text {cap }}$, with a $K_{1 / 2}$ of $3.3 \mathrm{~mm}$. Nonhydrolyzable analogs of ATP, adenylimidodiphosphate and adenosine 5'-O-(3-thio)-triphosphate, also increased $i_{\text {cap }}$. Neither $\mathrm{Mg}^{2+}$-free medium nor inhibitors of various kinases blocked the increase in $i_{\text {cap }}$ induced by ATP. The enhancing effect of ATP was also observed in inside-out patches of oocytes expressing vanilloid receptor 1 , a cloned capsaicin receptor. Single point mutations (D178N, K735R) within the putative Walker type nucleotide-binding domains abolished the effect of ATP. These results show that ATP increases $i_{\text {cap }}$ in sensory neurons by direct interaction with the CAP channel without involvement of phosphorylation.

Key words: capsaicin receptor; VR1; ATP; allosteric regulation; nucleotide-binding motif; pain
Capsaicin (CAP), the pungent ingredient of hot peppers, excites small sensory neurons and thereby causes pain or neurogenic inflammation (Bevan and Szolcsanyi, 1990; Szallasi and Blumberg, 1999). In cultured dorsal root ganglion (DRG) neurons, CAP has been shown to activate a nonselective cation channel and produce influx of cations (Bevan and Szolcsanyi, 1990; Oh et al., 1996). The activation of this cation channel is probably responsible for the excitation of a group of sensory neurons. A cDNA, vanilloid receptor 1 (VR1), that encodes a channel sensitive to CAP has recently been cloned (Caterina et al., 1997). A striking property of VR1 is that it is also activated by heat (Caterina et al., 1997; Tominaga et al., 1998). Another interesting property of VR1 is its activation by acid, indicating that protons can activate the channel (Tominaga et al., 1998). It is now known that disruption of VR1 gene reduces inflammation-induced heat hyperalgesia (Caterina et al., 2000; Davis et al., 2000). As a result, the view of the CAP receptor as a potential nociceptive heat and chemical sensor has gained a wide acceptance (Kress and Zeilhofer, 1999; Szallasi and Blumberg, 1999; Caterina et al., 2000; Davis et al., 2000).

Recently, endogenous lipids such as anandamide and various metabolic products of lipoxygenases such as 12-hydroperoxyeicosatetraenoic acid and leukotriene $\mathrm{B}_{4}$ have been shown to activate the CAP channel (Zygmunt et al., 1999; Hwang et al., 2000). The three-dimensional structure of 12-hydroperoxyeicosatetraenoic acid, one of the lipoxygenase products, was found to superimpose reasonably well with that of capsaicin, suggesting that these lipids may potentially act as endogenous capsaicin-like substances (Hwang et al., 2000).

During the course of our studies on the CAP channel, we observed that the channel activity in the cell-attached state with CAP in the pipette is always significantly higher than that after

\footnotetext{
Received June 19, 2000; revised Aug. 24, 2000; accepted Aug. 31, 2000.

This work was supported by National Creative Research Initiatives Program and in part by a Biotech Grant of Korea Science Technology and Engineering Planning Institution. We thank Dr. Donghee Kim for his critical reading of this manuscript.

Correspondence should be addressed to Uhtaek Oh, Sensory Research Group, Creative Research Initiatives, Seoul National University, College of Pharmacy, Kwanak, Shinlim San 56-1, Seoul 151-742, Korea. E-mail: utoh@plaza.snu.ac.kr.

Dr. Kwak's present address: Department of Physiology and Biophysics, College of Medicine, Seoul National University, Yongon-dong 28, Chongno, Seoul 110-744, Korea.

Copyright (C) 2000 Society for Neuroscience $0270-6474 / 00 / 208298-07 \$ 15.00 / 0$
}

formation of the inside-out state. This difference in channel activity could not be explained by a change in membrane potential or ionic composition. Therefore, we speculated that there exists a cytosolic substance that helps to maintain the channel activity at a higher level and that its washout reduces channel activity. Activity of many ion channels is often modulated by phosphorylation (Levitan, 1994). For example, activity of large conductance $\mathrm{Ca}^{2+}$-activated $\mathrm{K}^{+}$channel in the brain increases after the addition of ATP via phosphorylation mediated by cAMP-dependent protein kinase A (PKA) (Baraban et al., 1985; Chung et al., 1991) or protein kinase C (PKC) (De Peyer et al., 1982; Ewald et al., 1985; Kume et al., 1989).

In this study, we tested the hypothesis that intracellular ATP also modulates CAP channel activity in sensory neurons and examined the underlying molecular mechanism. We report here that ATP, although not an activator by itself, increases the CAP channel activity by directly interacting with the two putative Walker type nucleotide-binding sites, with no evidence of phosphorylation. Thus, intracellular ATP upregulates CAP channel activity in the intact native state and probably augments the nociceptive signal.

\section{MATERIALS AND METHODS}

Cell culture. Primary cultures of dorsal root ganglion neurons isolated from 1- or 2-d-old neonatal rats were used for recording single-channel currents as described previously (Hamill et al., 1981; Oh et al., 1996; Jung et al., 1999). Briefly, dorsal root ganglia from all levels of thoracic and lumbar spinal cord of neonatal rats were collected in a cold washing solution (mixture of DMEM and F-12; Life Technologies, Grand Island, NY). Ganglia were then incubated for $30 \mathrm{~min}$ in culture medium containing 1 $\mathrm{mg} / \mathrm{ml}$ collagenase (Worthington, Freehold, NJ) at $37^{\circ} \mathrm{C}$. The culture medium was a mixture of DMEM and F-12 solution containing $10 \%$ fetal calf serum (Life Technologies), $1 \mathrm{~mm}$ sodium pyruvate, 50-100 ng/ml nerve growth factor (Boehringer Mannheim, Indianapolis, IN), and 100 $\mathrm{U} / \mathrm{ml}$ penicillin/streptomycin (Life Technologies). Ganglia were then washed three times with $\mathrm{Mg}^{2+}-$ and $\mathrm{Ca}^{2+}$-free HBSS (Life Technologies) and then incubated in HBSS containing $2.5 \mathrm{mg} / \mathrm{ml}$ trypsin (Life Technologies) at $37^{\circ} \mathrm{C}$ for $30 \mathrm{~min}$ followed by a $10 \mathrm{~min}$ centrifugation at $1000 \mathrm{rpm}$. The pellet was washed gently in culture medium and resuspended in the culture medium by gentle trituration. Suspended cells were plated on round glass coverslips pretreated with poly-L-lysine $(0.5 \mathrm{mg} / \mathrm{ml})$. Cells were incubated at $37^{\circ} \mathrm{C}$ in $95 \%$ air and $5 \% \mathrm{CO}_{2}$ mixture and used $2-4 \mathrm{~d}$ after plating.

Site-directed mutagenesis and expression of VR1 in oocytes. Mutations within the putative Walker A and B motifs found in the amino acid sequence of VR1 were introduced into pSDTF-VR1 (courtesy of T. P. Snutch of University of British Columbia) using recombinant PCR 
(Higuchi, 1990). Oligonucleotide primers for VR1-D178N (5'-CTGCTCCTGAACGTTGCCCGGAAGACA-3') or VR1-K735R (5'-CCTGACGGCAGGGATGACTACCGGTGG-3') mutants were designed to make single-base changes (italic). Mutations were produced in two steps. Briefly, two separate amplification reactions, one using sense primer HindIII (5'CCCAAGCTTGCCGCCACCATGGAACAACGGGCTAGC-3') and mutant antisense primer and the other using mutant sense primer and $K p n \mathrm{I}$ antisense primer $\left(5^{\prime}\right.$-CCGGTACCTTATTTCTCCCCTGGGAC-3'), were performed simultaneously for each mutant construct. The two reaction products were separated on a $1 \%$ agarose gel. DNA bands were excised and used as template for a second PCR amplification using HindIII and KpnI primers. For mutation in both Walker A and B motifs, VR1-K735R and VR1-D178N DNAs were digested with SacII and XbaI, respectively, and the $1.3 \mathrm{~kb}$ fragment of K735R and the $4.4 \mathrm{~kb}$ fragment of D178N were ligated. Mutations were verified by sequencing around the sites of the mutation. DNA was linearized downstream of VR1 cDNA at the XbaI site. cRNA was generated with SP6 promoter using Megascript in vitro transcription kit (Ambion, Austin, TX). The concentration of cRNA was measured from the absorbance at $260 \mathrm{~nm}$ and stored at $-70^{\circ} \mathrm{C}$ in RNasefree water.

Xenopus oocytes were surgically removed and defolliculated by treating oocytes with collagenase (type IA; Sigma, St. Louis, MO; $2 \mathrm{mg} / \mathrm{ml}$ ) for $1-1.5 \mathrm{hr}$ at room temperature in a solution containing (in $\mathrm{mM}$ ): $82 \mathrm{NaCl}$, $20 \mathrm{MgCl}_{2}, 5 \mathrm{HEPES}$, and $2 \mathrm{KCl}, \mathrm{pH} 7.5$. Each oocyte was injected with $\sim 50 \mathrm{nl}$ of cRNA ( $\sim 25 \mathrm{ng}$ of cRNA) encoding wild-type or mutant VR1 Three to five days after the injection, vitelline membrane of oocytes was removed by incubating the oocytes with protease (type XXVII; Sigma; 0.5 $\mathrm{mg} / \mathrm{ml}$ ) for $10 \mathrm{~min}$. The action of protease was terminated after washing in a solution containing a trypsin inhibitor $(1 \mathrm{mg} / \mathrm{ml}$; type II-S; soybean; Sigma). The stripped oocytes were then placed in a recording chamber for single-channel recording.

Electrophysiology. Gigaseals were formed with borosilicate glass capillaries (Narishige, Tokyo, Japan) coated with Sylgard (Dow Corning, Midland, MI). Tip resistances of the glass pipettes used were $\sim 5 \mathrm{M} \Omega$. For singlechannel recording, inside-out patches isolated from cultured sensory neurons or oocytes were formed as described previously (Hamill et al., 1981). Single-channel currents were recorded with a patch-clamp amplifier (Axopatch 1D; Axon Instruments, Foster City, CA), filtered at $2.5 \mathrm{kHz}$ with an eight pole, low-pass Bessel filter (Frequency Device, Haverhill, MA), digitized at $37 \mathrm{kHz}$ with a digital data recorder (Instrutech, Great Neck, $\mathrm{NY}$ ), and stored on videotapes. Digitized data were imported to a computer to obtain mean open times, amplitude histograms, and open probability $(P o)$. The half-amplitude algorithm in Fetchan (pClamp; Axon Instruments) was used to detect open events. Using pClamp software, $P o$ was calculated as the value equal to the area under the curve representing open events divided by the sum of the areas under the curves representing open and closing events. Channel activity was calculated as NPo, where $N$ is the number of observed channels in the patch. NPo of single-channel currents was determined only from membrane patches that contained less than six CAP-activated channels.

Solutions and chemicals. For recording single-channel currents in cultured DRG neurons or oocytes, control bath and pipette solutions contained (in mM): $140 \mathrm{NaCl}, 2 \mathrm{MgCl}_{2}, 5$ EGTA, and 10 HEPES, pH 7.2. $\mathrm{Mg}^{2+}$-free solution contained (in $\mathrm{mm}$ ): $140 \mathrm{NaCl}, 5 \mathrm{EDTA}$, and 10 HEPES, $\mathrm{pH}$ 7.2. The bath solution having $\mathrm{K}^{+}$as the charge carrier contained (in mM): $140 \mathrm{KCl}, 2 \mathrm{MgCl}_{2}, 5$ EGTA, and 10 HEPES, pH 7.2 . CAP was dissolved and stored as $10 \mathrm{~mm}$ stock solution in $100 \%$ ethanol. ATP, adenylimidodiphosphate, adenosine 5 - $O$-(3-thio)-triphosphate, 2-deoxy ATP, and other nucleotide triphosphates were dissolved in water $\mathrm{pH} 7.0$, stored as $100 \mathrm{~mm}$ or $10 \mathrm{~mm}$ stock solutions, and kept at $-70^{\circ} \mathrm{C} . \mathrm{H}-7$ or other kinase inhibitors (Research Biochemicals, Natick, MA) were stored at $10 \mathrm{~mm}$ as stock solutions. $\mathrm{A} \mathrm{Ca}^{2+}$-calmodulin dependent kinase II (CaMKII) inhibitor, CaMKII 281-301 (Research Biochemicals), was prepared in the control bath solution immediately before use. All electrophysiological experiments were performed at room temperature.

All values are expressed as mean \pm SEM. ANOVA followed by a Tukey post hoc test was used for analysis of multiple comparisons among means. $p<0.05$ was considered significant.

\section{RESULTS}

\section{ATP stimulates CAP channel activity $\left(i_{\text {cap }}\right)$}

In cell-attached patches with CAP in the pipette, nonselective ion channels with properties of $i_{\text {cap }}$ are activated, as reported previously (Fig. 1A; Oh et al., 1996). Under the cell-attached condition, the channel activity is maintained with little or no desensitization in the absence of external $\mathrm{Ca}^{2+}$. However, after formation of inside-out patches, a marked decrease in channel activity is observed whether the bath solution contains $140 \mathrm{mM} \mathrm{Na}^{+}$or $\mathrm{K}^{+}$. Application of $1 \mathrm{~mm}$ ATP to the cytoplasmic side of the membrane elevated the channel activity to levels close to that observed in the cell-attached state (Fig. $1 A$, graph in inset). These observations indicate that intracellular ATP upregulates the activity of CAP channels when they are in the open state.
A

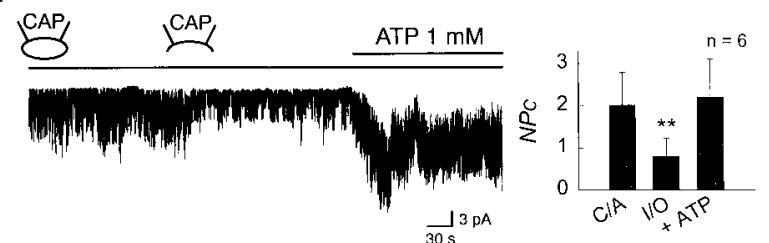

B

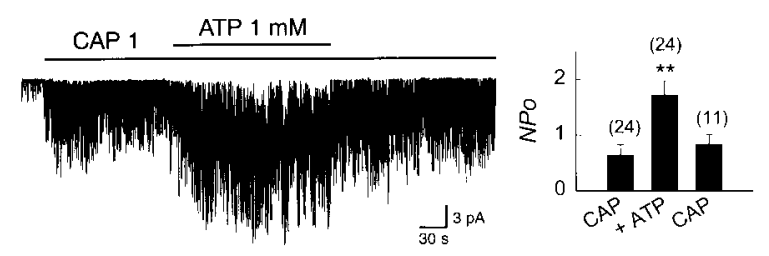

C

CAP 1

ATP $1 \mathrm{mM}$

CAP 1

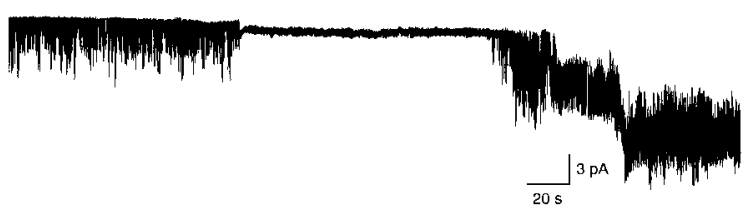

Figure 1. ATP-induced increase in CAP-activated channel activity in dorsal root ganglion neurons. $A$, A cell-attached patch formed with CAP in the pipette shows activation of single-channel currents $\left(i_{\text {cap }}\right)$. Inside-out patch was subsequently formed. ATP $(1 \mathrm{mM})$ was then applied to the cytoplasmic side of the membrane. The graph in the inset shows channel activity $(\mathrm{NPO})$ under three different patch conditions. Bars represent mean \pm SEM. Concentration of CAP is expressed in micromoles $(* * p<$ $0.01) . \bar{B}$, An inside-out patch was formed with no CAP in the pipette. Application of $1 \mu \mathrm{M}$ CAP to the bath solution activated $i_{c a p}$. Addition of $1 \mathrm{~mm}$ ATP to the bath caused a significant increase in $i_{\text {cap }}$. Membrane potential was $-60 \mathrm{mV}$. Graph in the inset summarizes the effects of ATP on $i_{\text {cap }}$. Numbers on the bars represent number of experiments $(* * p<0.01) . C$, Application of $1 \mathrm{~mm}$ ATP alone to the bath of an inside-out patch did not activate $i_{\text {cap }}$, but addition of $1 \mu \mathrm{M}$ CAP to the bath rapidly activated $i_{\text {cap }}$.

Figure $1 B$ shows an inside-out patch in which the cation channels were activated with CAP applied to the cytoplasmic side of the membrane. Stable and prolonged activation of $i_{\text {cap }}$ is normally observed in the continuous presence of $1 \mu \mathrm{M}$ CAP to the bath solution (up to $40 \mathrm{~min}$ ). In the same patch, addition of $1 \mathrm{mM}$ ATP to the bath together with $1 \mu \mathrm{M}$ CAP resulted in a 2.6-fold increase in activity of the channel $(N P O=0.65 \pm 0.18$ vs $1.72 \pm 0.26 ; p<$ $0.001 ; n=24$; Fig. $1 B$, graph in inset). Similar enhancing effect of ATP on $i_{\text {cap }}$ was observed when the charge carrier was changed from $\mathrm{Na}^{+}$to $\mathrm{K}^{+}(2.1$-fold increase; $n=4)$. In patches in which CAP was initially not present and therefore $i_{\text {cap }}$ not open, application of $1 \mathrm{~mm}$ ATP alone failed to activate $i_{\text {cap }}(n=4)$. When CAP was subsequently added in the presence of ATP $(1 \mathrm{mM}), i_{\text {cap }}$ was quickly activated in same patches (Fig. $1 C$ ). These results show that ATP itself is not an activator of $i_{\text {cap }}$ but is a positive modulator of the CAP channel.

Figure 2 shows that ATP affects open and closed time durations of the channel. Both open and closed time durations activated by CAP could be fitted well by two exponential functions. In control condition, $1 \mu \mathrm{M}$ CAP activated the channel with open time constants of $0.53 \pm 0.07$ and $5.20 \pm 1.85 \mathrm{msec}$ and with closed time constants of $0.19 \pm 0.03$ and $7.0 \pm 2.19 \mathrm{msec}(n=7)$. After treatment with $1 \mathrm{mM}$ ATP, the open time constants increased to $0.94 \pm 0.21$ and $7.93 \pm 0.39 \mathrm{msec}$, whereas the closed time constants decreased to $0.13 \pm 0.02$ and $2.2 \pm 0.51 \mathrm{msec}(n=7)$. These results show that ATP increases the channel activity via prolongation of the open time duration and shortening of the closed time duration.

\section{Concentration-response relationship of the ATP effect}

A concentration-dependent effect of ATP was obtained by applying increasing concentrations of ATP from 0.06 to $20 \mathrm{~mm}$ to inside-out 
A

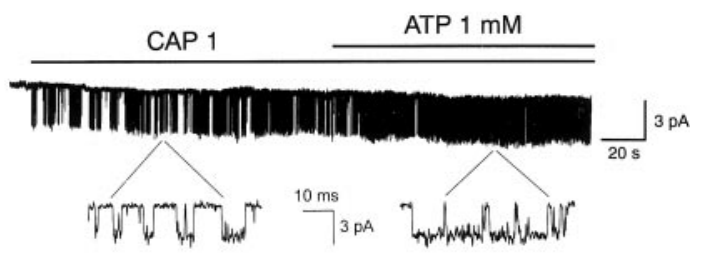

B

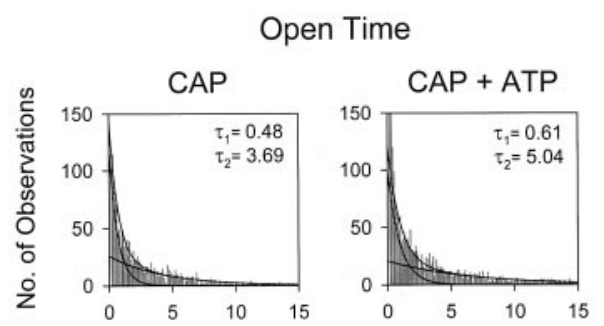

C

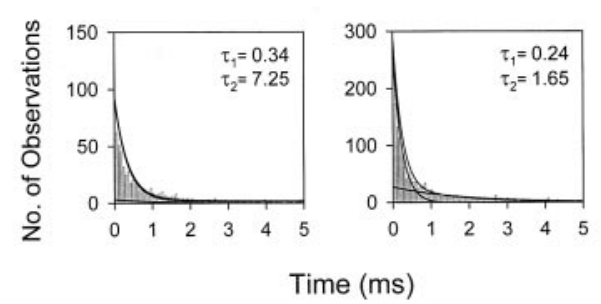

Figure 2. Effect of ATP on the mean open and closed time durations of $i_{\text {cap }}$. A, A representative trace of $i_{\text {cap }}$ augmented by addition of $1 \mathrm{~mm}$ ATP in an inside-out patch containing a single channel. $B$, Changes in the open time durations of $i_{\text {cap }}$ before and after addition of $1 \mathrm{~mm}$ ATP. Histograms of the open time duration were best fitted by two exponential functions. $C$, Changes in the closed time durations of $i_{\text {cap }}$ before and after addition of 1 mM ATP. Histograms of the closed time duration were best fitted by two exponential functions.

patches containing CAP channels already activated with $1 \mu \mathrm{M}$ CAP. With each application of [ATP], a stable channel activity was obtained for 1-2 min. Channel activity started to increase at $0.3 \mathrm{~mm}$ ATP and continued to increase even up to $20 \mathrm{~mm}$. Near-maximal effect was observed with $10 \mathrm{~mm}$ ATP. Fold increase in channel activity obtained at each concentration of ATP was plotted as a function of [ATP]. Data points were fitted to the Hill equation of the form:

$$
\text { Fold increase }=1+\frac{F_{\mathrm{MAX}}}{1+\left(K_{\mathrm{D}} /[\mathrm{ATP}]\right)^{n}},
$$

where $F_{\mathrm{MAX}}$ is the maximal fold increase obtained after addition of $20 \mathrm{~mm}$ ATP, $K_{\mathrm{D}}$ is the half-maximal concentration of ATP, and $n$ is the Hill coefficient. As shown in Figure 3, the mean $K_{\mathrm{D}}$ obtained from the plot was $3.3 \mathrm{~mm}$, and the Hill coefficient was 0.7. The high $K_{\mathrm{D}}$ value obtained is two orders of magnitude greater than that normally required for a kinase-mediated phosphorylation reaction (Krebs and Beavo, 1979; Francis and Corbin, 1994; Hilgemann, 1997).

\section{Role of $\mathrm{Mg}^{2+}$ and kinases}

ATP often serves as a donor of a phosphate group to proteins. Therefore, the increase in $i_{c a p}$ by ATP may be via phosphorylation of the CAP channel. $\mathrm{Mg}^{2+}$ is a necessary cofactor for the action of kinases (Eckstein, 1985; Levitan, 1994). Therefore, to determine whether the increase in $i_{\text {cap }}$ by ATP depends on a kinase-mediated phosphorylation of the channel, the response of $i_{c a p}$ to ATP was tested in a $\mathrm{Mg}^{2+}$-free solution. In an inside-out patch perfused with a solution containing no free $\mathrm{Mg}^{2+}$ (5 mM EDTA without added $\mathrm{Mg}^{2+}$ ), $1 \mu \mathrm{M}$ CAP was first applied to activate $i_{\text {cap }}$. Under this condition, further application of $1 \mathrm{mM}$ ATP augmented $i_{c a p}$ 3.0 -fold $(\mathrm{NPo}=0.28 \pm 0.07$ vs $0.85 \pm 0.14 ; n=5)$. Replacing with

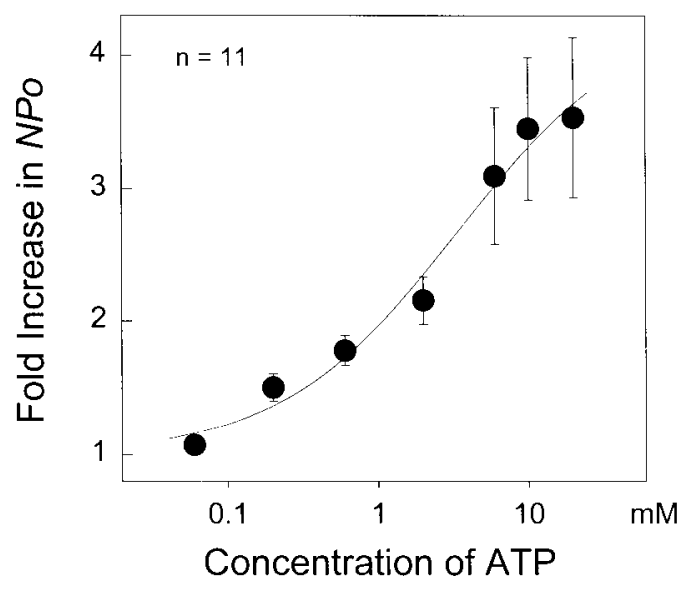

Figure 3. Concentration-dependent effect of ATP on $i_{c a p}$. Fold increase in NPo of the CAP channel is plotted as a function of ATP concentration. Data points $(n=11)$ were fitted to the Hill's equation, as described in Results.

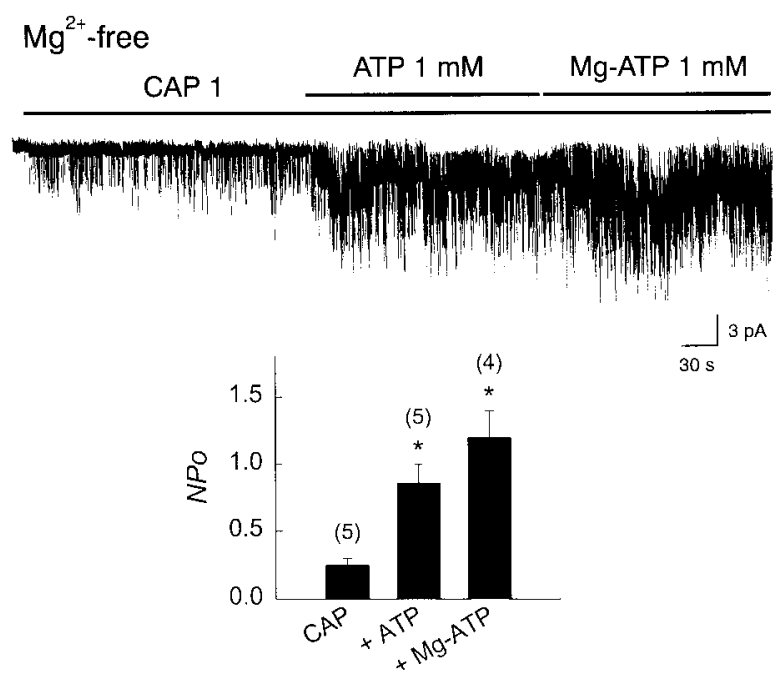

Figure 4. ATP-induced increase in $i_{c a p}$ in $\mathrm{Mg}^{2+}$-free solution. CAP channels were activated in an inside-out patch in solution containing no $\mathrm{Mg}^{2+}$. ATP (1 mM) was further added. When channel activity was at steady state, $\mathrm{Mg}^{2+}$-free ATP was replaced with Mg-ATP. The graph in the inset shows NPO in the presence and absence of ATP. Numbers on the bars represent number of experiments. Concentration of CAP is expressed in micromoles. Bars represent mean \pm SEM. Asterisk indicates a significant difference from the first bar $(p<0.05)$.

$1 \mathrm{~mm} \mathrm{Mg-ATP} \mathrm{produced} \mathrm{no} \mathrm{further} \mathrm{increase} \mathrm{in} i_{c a p}$ (Fig. 4). Therefore, the upregulation of $i_{c a p}$ by ATP does not require $\mathrm{Mg}^{2+}$, and this is consistent with the view that the ATP effect does not involve phosphorylation of the channel by a kinase.

To provide additional evidence that phosphorylation is not involved, inhibitors of various protein kinases were applied to membrane patches together with $1 \mu \mathrm{M}$ CAP, and then 1 mM ATP was applied subsequently. Pretreatment with $20 \mu \mathrm{M} \mathrm{H}-7$, a nonspecific inhibitor of protein kinases $\mathrm{A}, \mathrm{C}$, and $\mathrm{G}$ for $\sim 7 \mathrm{~min}$ failed to block the increase in $i_{\text {cap }}$ by ATP (Fig. 5A). We tested the effect of genistein and lavendustin $\mathrm{A}$, inhibitors of tyrosine kinase, on CAP channel activity. Interestingly, genistein $(20 \mu \mathrm{M})$ or lavendustin A $(1 \mu \mathrm{M})$ inhibited $i_{\text {cap }}$ when applied with CAP such that we could not test the effect of ATP. We therefore used staurosporine, a nonspecific kinase inhibitor known to block various kinases, including tyrosine kinases (Fallon, 1990; Badwey et al., 1991). Staurosporine $(1 \mu \mathrm{M})$ also failed to block the ATP effect on $i_{\text {cap }}$ (Fig. 5B). We also applied a peptide inhibitor of $\mathrm{Ca}^{2+}$-calmodulin dependent kinase II, CaMKII 281-301 $(10 \mu \mathrm{M})$, to the bath along with ATP and CAP. CaMKII 281-301 did not block the increase in $i_{\text {cap }}$ produced 
A

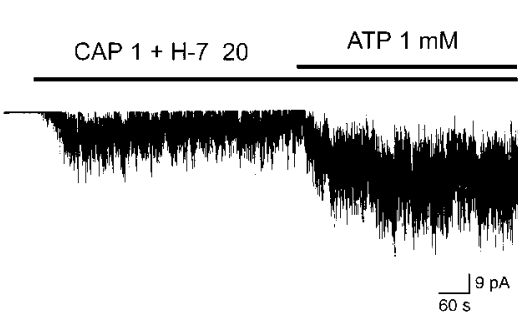

C
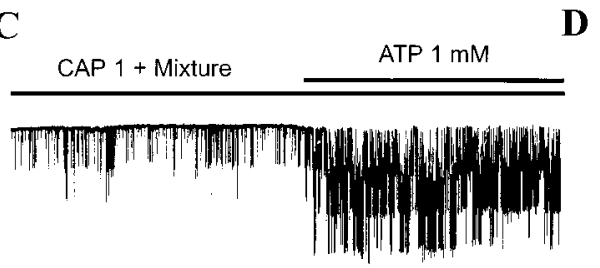

$\frac{ل^{3} \mathrm{pA}}{30 \mathrm{~s}}$
B

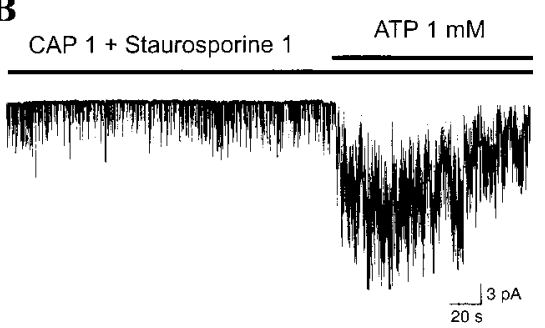

Figure 5. Protein kinase inhibitors do not block ATPinduced increase in $i_{\text {cap }}$. $A$, An inside-out patch was formed, and both $1 \mu \mathrm{M}$ CAP and $20 \mu \mathrm{M} \mathrm{H}-7$ were added to the bath solution. After several minutes, ATP was further applied. Concentration is expressed in micromoles. $B$, Same as in $A$ except that $1 \mu \mathrm{M}$ staurosporine was used instead of $\mathrm{H}-7$ to block tyrosine kinases. $C$, The mixture of $\mathrm{H}-7(20 \mu \mathrm{M})$, staurosporine $(1 \mu \mathrm{M})$, and a $\mathrm{Ca}^{2+}$-calmodulin dependent kinase II inhibitor (CaMKII 281-301; $10 \mu \mathrm{M}$ ) was applied to the patch membrane. ATP was further applied. $D$, Summary of effects of kinase inhibitors on the effect of ATP. In each experiment, channel activity $(N P o)$ obtained in the presence of $1 \mu \mathrm{M}$ CAP, $1 \mathrm{~mm}$ ATP, and each inhibitor of protein kinase was normalized to $N P o$ obtained with the application of $1 \mu \mathrm{M}$ CAP alone. Numbers on top of the bars represent number of experiments. Bars represent mean \pm SEM. Asterisk indicates a significant difference from the first bar $(p<0.05)$.

by ATP (Fig. $5 D)$. In the presence of a mixture of $\mathrm{H}-7(20 \mu \mathrm{M})$, staurosporine $(1 \mu \mathrm{M})$ and the peptide inhibitor of CaMKII (10 $\mu \mathrm{M})$, CAP was able to produce a typical activation of the CAP channel. The mixture of inhibitors failed to block the increase in $i_{c a p}$ produced by ATP (Fig. $5 C$ ), providing further evidence that ATP augment $i_{c a p}$ via a pathway that does not involve phosphorylation by protein kinase $\mathrm{A}, \mathrm{C}$, and $\mathrm{G}, \mathrm{Ca}^{2+}$-calmodulin dependent kinase II, and possibly tyrosine kinases.

\section{Effects of ATP analogs and other nucleoside triphosphates}

To further examine the nature of ATP-dependent modulation of the CAP receptor activity, we studied the effect of nonhydrolyzable analogs of ATP and other nucleoside phosphates. CAP channels were first activated with $1 \mu \mathrm{M} \mathrm{CAP}$ in inside-out patches. As shown in Figure $6 A$, further application of $1 \mathrm{~mm}$ adenylimidodiphosphate (AMP-PNP) to the cytoplasmic side of inside-out patches resulted in a significant increase in channel activity (3.0-fold; $0.48 \pm 0.20 \mathrm{vs}$ $1.42 \pm 0.41 ; p<0.05 ; n=7)$. When AMP-PNP was washed off and $1 \mathrm{~mm}$ ATP applied, no further increase in channel activity was present. This indicates that the increase in channel activity by ATP does not require hydrolysis of ATP. Another nonhydrolyzable analog of ATP, adenosine 5'-O-(3-thio)-triphosphate (ATP $\gamma \mathrm{S})$, also markedly augmented the channel activity 3.0 -fold $(0.70 \pm 0.21$ vs $2.07 \pm 0.55 ; p<0.05 ; n=4$ ) in a reversible manner (Fig. $6 B$ ). Nucleoside triphosphates other than ATP such as GTP, UTP, CTP, or ITP (1 mM each) failed to significantly alter $i_{\text {cap }}$ (Fig. 6C), indicating that only ATP augments the $i_{c a p}$. 2-Deoxy ATP (1 mM) was as effective as ATP in increasing $i_{\text {cap }}$. These results suggest that ATP augment $i_{\text {cap }}$ by an allosteric mechanism that involves binding of ATP to a site that is distinct from the activation site.

\section{Removal of the ATP effect by mutations in the nucleotide-binding domains of VR1}

The cloned CAP channel VR1 possesses two putative sequences that are homologous to the Walker A and B type nucleotidebinding domains (Walker et al., 1982). Walker B type sequence is found in the $\mathrm{N}$ terminus, and the Walker A type sequence is found in the $\mathrm{C}$ terminus (Fig. 7A). To determine whether ATP binds to one or both of these potential nucleotide-binding domains to produce its modulatory effect, invariant amino acids known to be critical for nucleotide binding were mutated. Wild-type and mutant VR1 were expressed in oocytes, and the effects of both CAP and ATP were examined. In inside-out patches isolated from oocytes expressing wild-type VR1, intracellular application of $0.2 \mu \mathrm{M}$ CAP activated $i_{\text {cap }}$. In the same patch, addition of $2 \mathrm{mM}$ ATP augmented $i_{\text {cap }} 2.3 \pm 0.2$-fold $(p<0.005 ; n=7)$, showing that ATP also
$\mathbf{A}$

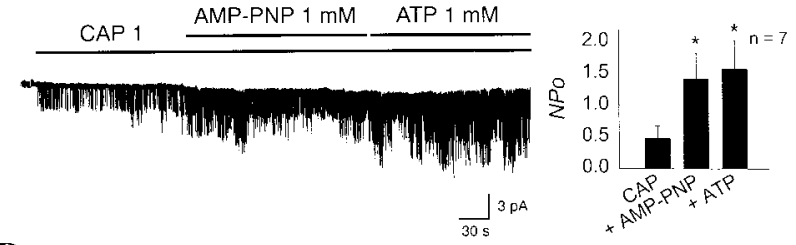

B
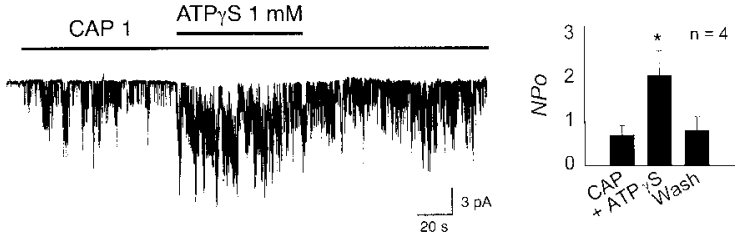

C

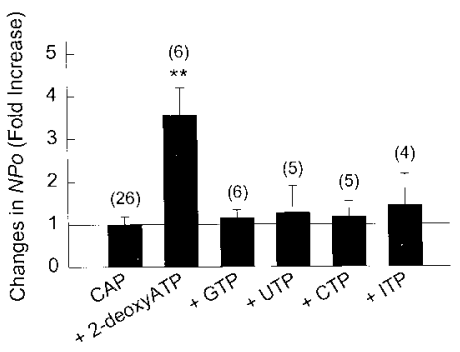

Figure 6. Nonhydrolyzable analogs of ATP activate $i_{c a p}$. A, In an insideout patch, $1 \mu \mathrm{M}$ CAP was applied to activate $i_{c a p}$. Further application of AMP-PNP resulted in a significant increase in channel activity. Application of ATP did not produce a further increase $\left({ }^{*} p<0.05\right)$. B, Another nonhydrolyzable analog of ATP, ATP $\gamma \mathrm{S}$, also increased $i_{\text {cap }}$ when applied to patches together with $1 \mu \mathrm{M} \mathrm{CAP}\left({ }^{*} p<0.05\right)$. $C$, A summary of the effects produced by various nucleoside triphosphates (1 mM) and 2-deoxy ATP $(1 \mathrm{mM})$ on $i_{\text {cap }}$. Bars represent mean \pm SEM. Asterisks indicate a significant difference from the first bar $(p<0.01)$.

augments VR1 activity (Fig. $7 B$ ). To determine the contribution of the Walker A-type motif, we mutated the lysine residue (K735) that is invariant among glycine-rich Walker A-type motifs (GXXXXGK) to another positively charged arginine (Walker et al., 1982; Driscoll et al., 1995; Hung et al., 1998). In oocytes injected with cRNA of the mutant VR1 (VR1-K735R), $0.2 \mu \mathrm{M}$ CAP produced activation of $i_{\text {cap }}$, but further addition of 2 mM ATP failed to augment $i_{\text {cap }}$ (Fig. 7C).

A putative Walker-type $\mathrm{B}$ motif is present in the cytoplasmic $\mathrm{N}$ 
A

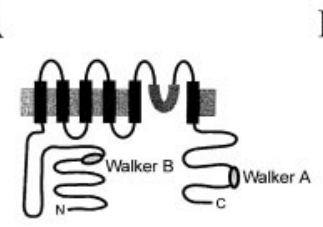

A:- ${ }^{726}$ LQVGFTPDGKंDDYRW ${ }^{740}-$

B:- ${ }^{171}$ DTIALLLDEVARKTDS ${ }^{185}$

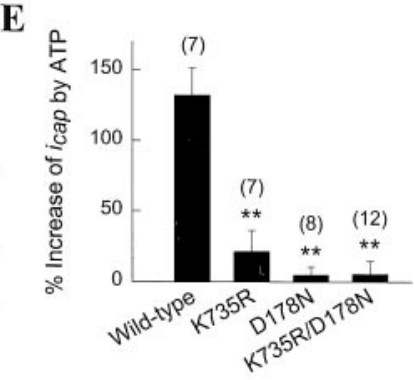

B VR1-Wild type

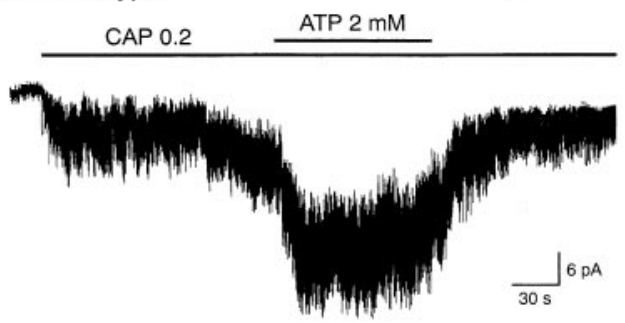

C VR1-K735R

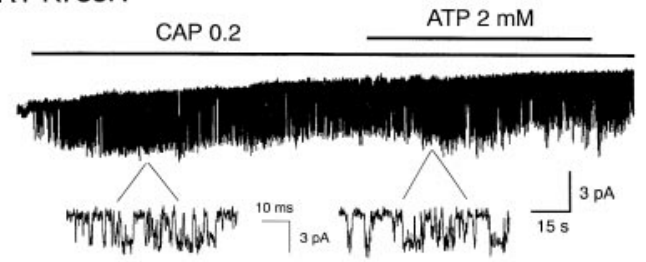

D VR1-D178N

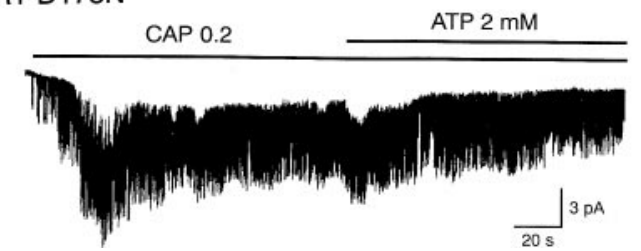

Figure 7. Mutations of amino acids in the putative nucleotide-binding region block the ATP effect. $A$, Predicted topology of VR1. Two putative Walker A- and B-type domains are shown. B, Wild-type VR1 was expressed in oocytes. In an inside-out patch, application of CAP caused activation of VR1. Further addition of $2 \mathrm{mM}$ ATP produced a marked increase in channel activity. $C$, Lysine at position 735 of VR1 was substituted with arginine (K735R). ATP failed to increase the channel activity in patches expressing VR1-K735R. Activation by CAP was not affected. $D$, Mutations at putative Walker B motif (VR1-D178N) abolished the ATP effect on $i_{c a p}$. $E$, Summary of effects of ATP on $i_{\text {cap }}$ in oocytes expressing the wild-type or mutant VR1. Numbers on top of the bars represent number of experiments. Bars represent mean \pm SEM. Asterisks indicate a significant difference from the control value $(p<0.01)$.

terminus of VR1. Here, four to six hydrophobic amino acids are followed by a highly conserved aspartate residue (Walker et al., 1982; Saraste et al., 1990; Hung et al., 1998). We mutated the highly conserved aspartate residue to asparagine, a structurally similar but uncharged amino acid. In oocytes expressing this mutant (VR1D178N), CAP was able to activate $i_{\text {cap }}$, but ATP failed to further increase the channel activity (Fig. 7D). As expected, ATP did not augment $i_{c a p}$ when mutations (VR1-D178N/K735R) were made at both sites (Fig. $7 E$ ). These results show that interaction of ATP with both putative nucleotide-binding domains that lie in the $\mathrm{N}$ and $\mathrm{C}$ termini are necessary for the enhancing effect of ATP to occur.

\section{DISCUSSION}

CAP-activated channels that exist in a group of small sensory neurons are believed to be involved in the generation of multiple forms of nociceptive neural signals and are now considered as molecular pain transducers for various noxious stimuli (Kress and Zeilhofer, 1999; Szallasi and Blumberg, 1999; Caterina et al., 2000;
Davis et al., 2000). Thus, study of the mechanisms by which the CAP receptor is modulated by various factors will greatly aid in understanding the cellular processes underlying nociception. In the present study, we show that the CAP receptor is modulated by intracellular ATP in isolated membrane patches of cultured sensory neurons. We have provided evidence that ATP interacts with the putative nucleotide-binding domains of the CAP receptor to enhance the channel activity. Our results are consistent with the view that ATP augments CAP-activated channel activity by an allosteric mechanism.

\section{Activation of the CAP-activated channel by ATP analogs}

AMP-PNP and ATP $\gamma$ S are nonhydrolyzable ATP analogs that are frequently used to test whether a reaction involves phosphorylation and requirement for ATP hydrolysis. For example, AMP-PNP has no apparent effect on the activity of $\mathrm{Ca}^{2+}$-activated $\mathrm{K}^{+}$channel that is known to be modulated only by phosphorylation by kinases (Chung et al., 1991; Esguerra et al., 1994). Our results that AMPPNP augments $i_{c a p}$ suggest that the modulation of the CAP receptor by ATP occur via a phosphorylation-independent pathway. $\mathrm{ATP} \gamma \mathrm{S}$, another nonhydrolyzable analog of ATP, is a substrate for most kinases but a poor substrate for phosphatases (Eckstein, 1985). Therefore, the effect of ATP $\gamma \mathrm{S}$ is generally irreversible and persistent such as that observed with a Maxi-K ${ }^{+}$channel (Chung et al., 1991; Esguerra et al., 1994). In our study, ATP $\gamma \mathrm{S}$ was able to increase $i_{\text {cap }}$ in cultured sensory neurons, but this effect of ATP $\gamma \mathrm{S}$ was reversible (Fig. $6 B$ ), suggesting that ATP $\gamma \mathrm{S}$ interact with the CAP receptors as an allosteric modulator rather than a phosphorothionate donor. These results, together with those showing that $\mathrm{Mg}^{2+}$ is not required and protein kinase inhibitors do not block the effect of ATP strongly suggest that modulation of the CAP receptor channel by ATP involve a binding site.

\section{Lack of involvement of $\mathbf{P}_{\mathbf{2}} \mathbf{X}$ receptor and cytoskeleton}

$\mathrm{P}_{2} \mathrm{X}$ receptor, a ligand-gated ion channel activated by extracellular ATP, is present in sensory neurons and may be involved in mediating nociception via release of ATP or its congeners to the extracellular matrix (Valera et al., 1994; Chen et al., 1995). Recently, it was reported that $\sim 75 \%$ of VR1-expressing DRG neurons also possess ATP-sensitive $\mathrm{P}_{2} \mathrm{X}_{3}$ receptors (Guo et al., 1999). Thus, it is possible that the effect of intracellularly applied ATP observed in inside-out patches occurred via $\mathrm{P}_{2} \mathrm{X}$ receptors (Segula et al., 1996; Hansen et al., 1997; Freist et al., 1998) as a result of ATP translocation to the extracellular side of the membrane. This seems unlikely for several reasons. First, ATP is negatively charged in physiological solution and thus cannot cross the cell membrane easily. Second, the conductance of $\mathrm{P}_{2} \mathrm{X}$ channel is much smaller than that of the CAP-activated channels ( $\sim 20$ vs $45 \mathrm{pS})$, but such $\mathrm{P}_{2} \mathrm{X}$ channels were not observed. Finally, in patches containing the CAP receptor, application of $1 \mathrm{~mm}$ ATP alone to the bath failed to induce single-channel currents in cultured DRG neurons (Fig. 1C). However, it is still possible that the CAP receptor can lead to translocation of ATP only in the presence of external CAP. The possibility, however, seems unlikely because internal ATP (1 mM) still enhances $i_{c a p}$ activated by external CAP and ATP (data not shown). Therefore, one can rule out the involvement of $\mathrm{P}_{2} \mathrm{X}$ receptors in ATP-induced augmentation of the CAP receptor channel activity.

Many transporters or channels are anchored to the membrane by direct or indirect linkage to cytoskeletal proteins. Intracellular levels of ATP affect assembly of cytoskeletal protein such as actin (Calier, 1993). Depletion of ATP causes depolymerization of actins associated with the plasma membrane (Golenhofen et al., 1996). Thus, the enhancing effect of ATP on $i_{c a p}$ could involve cytoskeletal rearrangement and polymerization of actin. When cells were pretreated with cytochalasin B to disrupt the actin microfilaments, the ATP effect was still present (data not shown). Therefore, the ATP effect on the CAP channel does not involve actin polymerization. 


\section{Role of nucleotide-binding domains in the modulation of the CAP receptor by ATP}

Transporters and channels such as CFTR and sulfonylurea receptor possess ATP-binding cassettes (ABC) that bind nucleotides such as ATP (Nagel, 1999; Ueda et al., 1999). ABC transporters have two nucleotide-binding domains, Walker A and B motifs, and a signal sequence between their primary structures (Walker et al., 1982; Decottignies and Goffeau, 1997; Hung et al., 1998). VR1 does not have the typical nucleotide-binding domain repeats that ABC transporters or channels possess. However, VR1 contains each of the Walker A and B motifs, suggesting that ATP may potentially interact with these nucleotide-binding domains. Walker A motif forms a glycine-rich loop that is known to bind phosphate groups of ATP. Some variances in nucleotide sequences of the Walker motifs have been reported such as GXXGXGK(T/S) (Walker et al., 1982; Thomas et al., 1996), GXXXXGK (Driscoll et al., 1995), or GXXGXXK (Satishchandran et al., 1992), where $\mathrm{X}$ represents any amino acid. However, the lysine residue of the motifs is invariant (Walker et al., 1982; Driscoll et al., 1995; Thomas et al., 1996; Hung et al., 1998). The crystal structures of ATPases and ATP-binding proteins show that the invariant lysine interacts directly with the $\beta$ - and $\gamma$-phosphate groups of bound ATP (Story and Steitz, 1992; Hung et al., 1998). Replacing the lysine residue in the Walker A motif to other amino acids, including arginine, results in the loss of allosteric binding, ATP hydrolysis, and ligand translocation of ABC transporters (Shyamala et al., 1991; Hung et al., 1998; Ramjeesingh et al., 1999; Weinreich et al., 1999). In VR1, replacing the lysine residue with arginine also resulted in complete loss of the ATP effect.

Walker B motif is identified generally by a stretch of four to six hydrophobic amino acids followed by a highly conserved aspartic acid (Walker et al., 1982; Hung et al., 1998). Story and his colleagues have suggested that the invariant aspartate in the Walker B motif coordinates with $\mathrm{Mg}^{2+}$ in the Mg-ATP complex (Story and Steitz, 1992; Story et al., 1993). However, the crystal structure of the ATP-binding subunit of a histidine permease, an ABC transporter from prokaryote, reveals that the aspartate in Walker B motif interacts with the $\gamma$-phosphate group of ATP via a water molecule that is usually occupied by $\mathrm{Mg}^{2+}$ required for ATP hydrolysis (Hung et al., 1998). This suggests the possible interaction of the aspartate in the Walker B motif with ATP without coordination with the divalent ions. Regardless of the molecular species coordinating with the aspartic acid residue, mutation of the aspartic acid results in the loss of binding ability of nucleotide and transport, suggesting the functional requirement of the Walker B motifs (Minard et al., 1990; Shyamala et al., 1991; Senior and Al-Shawi, 1992; Hung et al., 1998). In VR1, Walker B motif is found in the IALLLD sequence within the $\mathrm{N}$ terminus of the cytoplasmic domains. In the present study, substitution of the invariant aspartate to asparagine at Walker B motif resulted in the loss of enhancing effect of ATP, without affecting the ability of CAP to activate $i_{c a p}$. These mutation studies show that ATP binding to both nucleotide-binding sites is critical for channel modulation. Because ATP itself does not activate the CAP receptor channel, but addition of ATP to CAP increases the open time duration, ATP may be considered an allosteric modulator that alters the channel conformation to a long-open state.

\section{Physiological role of intracellular ATP}

CAP receptor serves as a sensor for multimodal noxious stimuli, as partly shown in mice deficient of VR1 gene (Kress and Zeilhofer, 1999; Szallasi and Blumberg, 1999; Caterina et al., 2000; Davis et al., 2000). Therefore, activity of the channel may correlate with the intensity of signal transmission of pain. The allosteric modulation of $i_{c a p}$ by intracellular ATP reported here will clearly contribute to the regulation of sensitivity of the CAP channel to noxious stimuli. As shown in Figure 1 and also reported previously (Oh et al., 1996), activity of the CAP receptor is greater in cell-attached than in inside-out patches. The $\mathrm{EC}_{50}$ of CAP in activating CAP receptors determined from whole-cell experiments with DRG neurons is lower than that from isolated-membrane patches ( $0.7 \mathrm{vs} 1.1 \mu \mathrm{M})$ (Oh et al., 1996; Koplas et al., 1997). Our finding that intracellular ATP augments the CAP channel activity can explain such a difference. Because intracellular ATP in cells is normally kept at high concentration (4-5 mM), it seems likely that the CAP receptor is maintained in ATP bound state, providing the full activation of the CAP channel under physiological conditions. Because the $K_{\mathrm{D}}$ for the ATP effect is relatively high $(3.3 \mathrm{~mm})$, a decrease in $[\mathrm{ATP}]_{\mathrm{i}}$ produced by ischemia or hypoxia could in principle reduce the CAP channel activity by decreasing the modulatory influence of ATP.

Although we observed an allosteric modulation of the channel by ATP binding to the channel protein, we cannot completely exclude the possibility that ATP helps the CAP receptors undergo changes in activity via phosphorylation. In this regard, the role of PKA in sensitizing the CAP receptors has been suggested earlier (Lopshire and Nicol, 1998). Nevertheless, results of the present study performed in $\mathrm{Mg}^{2+}$-free condition, mimic of the effect by nonhydrolyzable ATP analogs, requirement of high [ATP], and interaction of ATP on the nucleotide-binding domains of VR1 indicate that a significant part of the ATP effect is mediated by a phosphorylationindependent mechanism. The precise physiological significance, however, of the ATP modulation of the channel in sensory neurons needs to be studied further.

\section{REFERENCES}

Badwey JA, Erickson RW, Curnutte JT (1991) Staurosporine inhibits the soluble and membrane-bound protein tyrosine kinases of human neutrophils. Biochem Biophys Res Commun 178:423-429.

Baraban JM, Snyder SH, Alger B (1985) Protein kinase C regulates ionic conductance in hippocampal pyramidal neurons: electrophysiological effects of phorbol ester. Proc Natl Acad Sci USA 82:2538-2542.

Bevan SJ, Szolcsanyi J (1990) Sensory neuron-specific actions of capsaicin: mechanism and applications. Trends Pharmacol Sci 11:330-333.

Calier M-F (1993) Dynamic actin. Curr Biol 3:321-323.

Caterina MJ, Schumacher MA, Tominaga M, Rosen TA, Levine JD, Julius D (1997) The capsaicin receptor: a heat-activated ion channel in the pain pathway. Nature 389:816-824.

Caterina MJ, Leffler A, Malmberg AB, Martin WJ, Trafton J, PetersenZeitz KR, Koltzenburg M, Basbaum AI, Julius D (2000) Impaired nociception and pain sensation in mice lacking the capsaicin receptor. Science 288:306-313

Chen CC, Akopian AN, Silvilotti L, Colquhoun D, Burnstock G, Wood JN (1995) $\mathrm{A} \mathrm{P}_{2} \mathrm{X}$ purinoceptor expressed by a subset of sensory neurons. Nature 377:428-431.

Chung SK, Reinhart PH, Martin BL, Brautigan D, Levitan IB (1991) Protein kinase activity closely associated with a reconstituted calciumactivated potassium channel. Science 253:560-562.

Davis JB, Gray J, Gunthorpe MJ, Hatcher JP, Davey PT, Overend P, Harries MH, Latcham J, Clapham C, Atkinson K, Hughes SA, Rance K, Grau E, Harper AJ, Pugh PL, Roger DC, Bingham S, Randall A, Sheardown SA (2000) Vanilloid receptor-1 is essential for inflammatory thermal hyperalgesia. Nature 405:183-187.

De Peyer JE, Cachelin AB, Levitan IB, Reuter H (1982) $\mathrm{Ca}^{2+}$-activated $\mathrm{K}^{+}$conductance in internally perfused snail neurons is enhanced by protein phosphorylation. Proc Natl Acad Sci USA 79:4207-4211.

Decottignies A, Goffeau A (1997) Complete inventory of the yeast ABC proteins. Nat Genet 15:137-145.

Driscoll WJ, Komatsu K, Strott CA (1995) Proposed active site domain in estrogen sulfotransferase as determined by mutational analysis. Proc Natl Acad Sci USA 92:12328-12332.

Eckstein F (1985) Nucleoside phosphorothioates. Annu Rev Biochem $54: 367-402$.

Esguerra M, Wang J, Foster CD, Adelman, North RA, Levitan IB (1994) Cloned $\mathrm{Ca}^{2+}$-dependent $\mathrm{K}^{+}$channel modulated by a functionally associated protein kinase. Nature 369:563-565.

Ewald D, Williams A, Levitan IB (1985) Modulation of single $\mathrm{Ca}^{2+}$. dependent $\mathrm{K}^{+}$channel activity by protein phosphorylation. Nature 315:503-506.

Fallon RJ (1990) Staurosporine inhibits a tyrosine protein kinases in human hepatoma cell membranes. Biochem Biophys Res Commun 170:1191-1196.

Freist W, Verhey JF, Stuhmer W, Gauss DH (1998) ATP binding sites of P2X channel proteins: structural similarities with class II aminoacyltRNA synthetases. FEBS Lett 434:61-65.

Francis S, Corbin JD (1994) Structure and function of cyclic nucleotidedependent protein kinases. Annu Rev Physiol 56:237-272.

Golenhofen N, Doctro RB, Bacallao R, Mandell LJ (1996) Actin and villin compartmentation during ATP depletion and recovery in renal cultured cells. Kidney Int 48:1837-1845.

Guo A, Vulchanova L, Wang J, Li X, Elde R (1999) Immunocytochemical localization of the vanilloid receptor 1 (VR1): Relationship to neuropep- 
tides, the $\mathrm{P}_{2} \mathrm{X}_{3}$ purinoceptor and IB4 binding sites. Eur J Neurosci 11:946-958.

Hamill OP, Marty A, Neher E, Sakmann B, Sigworth FJ (1981) Improved patch-clamp techniques for high-resolution current recording from cells and cell-free membrane patches. Pflügers Arch 391:85-100.

Hansen MA, Barden JA, Balcar VJ, Keay KA, Bennett MR (1997) Structural motif and characteristics of the extracellular domain of P2X receptors. Biochem Biophys Res Commun 236:670-675.

Higuchi R (1990) In: PCR protocols, a guide to methods and applications. pp 177-183. San Diego: Academic.

Hilgemann DW (1997) ATP-dependent regulation of ion transporters and channels: mechanisms and messengers. Annu Rev Physiol 59:193-220.

Hung L-W, Wang XW, Nikaido K, Liu P-Q, Ames GF-L, Kim SH (1998) Crystal structure of the ATP-binding subunit of an ABC transporter. Nature 396:703-707.

Hwang SW, Cho HW, Kwak J, Lee S-Y, Kang C-J, Jung J, Cho S, Min KH, Suh Y-G, Kim D, Oh U (2000) Direct activation of capsaicin receptors by products of lipoxygenases: Endogenous capsaicin-like substances. Proc Natl Acad Sci USA 97:6155-6160.

Jung J, Hwang SW, Kwak J, Lee S-Y, Kang C-J, Kim WB, Kim D, Oh U (1999) Capsaicin binds to the intracellular domain of a capsaicinactivated ion channel. J Neurosci 19:529-538.

Koplas PA, Rosenberg RL, Oxford GS (1997) The role of calcium in the desensitization of capsaicin responses in the rat dorsal root ganglion neurones. J Neurosci 17:3525-3537.

Krebs EG, Beavo JA (1979) Phosphorylation-dephosphorylation of enzymes. Annu Rev Biochem 48:923-959.

Kress M, Zeilhofer HU (1999) Capsaicin, protons and heat: new excitement about nociceptors. Trends Pharmacol Sci 20:112-118.

Kume H, Tokuno H, Tomita T (1989) Regulation of $\mathrm{Ca}^{2+}$-dependent $\mathrm{K}^{+}$-channel activity in tracheal myocytes by phosphorylation. Nature 341:152-154.

Levitan IB (1994) Modulation of ion channels by protein phosphorylation and dephosphorylation. Annu Rev Physiol 56:193-212.

Lopshire JC, Nicol GD (1998) The cAMP transduction cascade mediates the prostaglandin $E_{2}$ enhancement of the capsaicin-elicited current in rat sensory neurons: whole-cell and single-channel studies. J Neurosci 18:6081-6092.

Minard P, Bowen DJ, Hall L, Littlechild JA, Watson HC (1990) Sitedirected mutagenesis of aspartic acid 372 at the ATP binding site of yeast phosphoglycerate kinase: over-expression and characterization of the mutant enzyme. Protein Eng 3:515-521.

Nagel G (1999) Differential function of the two nucleotide binding domains on cystic fibrosis transmembrane conductance regulator. Biochim Biophys Acta 1461:263-274.

Oh U, Hwang SW, Kim D (1996) Capsaicin activates a non-selective cation channel in cultured neonatal rat dorsal-root ganglion neurons. J Neurosci 16:1659-1667.

Ramjeesingh M, Li C, Garami E, Huan L-J, Galley K, Wang Y, Bear CE
(1999) Walker mutations reveal loose relationship between catalytic and channel-gating activities of purified CFTR (cystic fibrosis transmembrane conductance regulator). Biochemistry 38:1463-1468.

Saraste M, Sibbald PR, Wittinghofer (1990) The P-loop-a common motif in ATP- and GTP-binding proteins. Trends Biochem Sci 15:430-434.

Satishchandran C, Hickman YN, Markham GD (1992) Characterization of the phosphorylated enzyme intermediate formed in the adenosine 5'-phosphosulfate kinase reaction. Biochemistry 31:11648-11688.

Segula P, Haghighi A, Soghomonian JJ, Cooper E (1996) A novel neuronal P2X ATP receptor ion channel with widespread distribution in the brain. J Neurosci 16:448-455.

Senior AE, Al-Shawi MK (1992) Further examination of seventeen mutations in Escherichia coli $\mathrm{F}_{1}$-ATPase subunit. J Biol Chem 267: 21471-21487.

Shyamala V, Baichwal V, Beall E, Ames GF-L (1991) Structure-function analysis of the histidine permease and comparison with cystic fibrosis mutations. J Biol Chem 266:18714-18719.

Story RM, Steitz TA (1992) Structure of the recA protein-ADP complex. Nature 355:374-376.

Story RM, Bishop DK, Klecker N, Steitz TA (1993) Structural relationship of bacterial RecA proteins to recombination proteins from bacteriophage T4 and yeast. Science 259:1892-1896.

Szallasi A, Blumberg PM (1999) Vanilloid (Capsaicin) receptors and mechanisms. Pharmacol Rev 51:159-212.

Thomas PM, Wohlk N, Huang E, Kuhnle U, Rabl W, Gagel RF, Cote GJ (1996) Inactivation of the first nucleotide-binding fold of the sulfonylurea receptor, and familial persistent hyperinsulinemic hypoglycemia of infancy. Am J Hum Genet 59:510-518.

Tominaga M, Caterina MJ, Malmberg AB, Rosen TA, Gilbert H, Skinner K, Raumann BE, Basbaum AI, Julius D (1998) The cloned capsaicin receptor integrates multiple pain-producing stimuli. Neuron 21:531-543.

Ueda K, Matsuo M, Tanabe K, Morita K, Kioka N, Amachi T (1999) Comparative aspects of the function and mechanism of SUR1 and MDR1 proteins. Biochim Biophys Acta 1461:305-313.

Valera S, Hussy N, Evans RJ, Adami N, North RA, Surprenant A, Buell G (1994) A new class of ligand-gated ion channel defined by P2X receptor for extracellular ATP. Nature 371:516-519.

Walker J, Saraste M, Runswick MJ, Gay NJ (1982) Distantly related sequences in the alpha- and beta-subunits of ATP synthase, myosin, kinases and other ATP-requiring enzymes and a common nucleotide binding fold. EMBO J 1:945-951.

Weinreich M, Liang C, Stillman B (1999) The Cdc6p nucleotide-binding motif is required for loading mcm proteins onto chromatin. Proc Natl Acad Soc USA 96:3441-3446.

Zygmunt PM, Petersson J, Andersson DA, Chuang H, Sorgard M, Di Marzo V, Julius D, Hogestatt ED (1999) Vanilloid receptors on sensory nerves mediate the vasodilator action of anandamide. Nature 400:452-457. 